\title{
Active Limit State Analysis of Soil Considering Displacement Effect of the Retaining Wall
}

\author{
Bin Peng ${ }^{1, a}$, Zhijun $\mathrm{Li}^{1}$, He Huang ${ }^{1}$, Hanyang Liu${ }^{1}$, Lian Fan ${ }^{1}$ and Zecheng $\mathrm{Chi}^{2}$ \\ ${ }^{1}$ Hubei electric power survey \& design institute, Wuhan 430040, China \\ ${ }^{2}$ Institute of Rock and Soil Mechanics, Chinese Academy of Sciences, Wuhan 430071, China
}

a519177924@qq.com

\begin{abstract}
Keywords: Active Limit State, Earth Pressure, Displacement Mode, Retaining Wall.
Abstract. The earth pressure of the retaining wall is related to the displacement mode. The displacement mode determines the characteristics of the progressive failure forms. Based on the analysis of the possible displacement modes of the rigid retaining wall, the active yield characteristics and the progressive development model of the post-wall soil under different displacement modes of the retaining wall are quantitatively analyzed by means of finite element method. The relationship between the limit state and the wall displacement is proposed, and the criterion of the ultimate active earth pressure state is put forward.
\end{abstract}

\section{Introduction}

The key to the development of the design theory of the deep foundation pit engineering is correctly calculating the earth pressure acting on the envelope. In the conventional design, the earth pressure is generally given to the state of the Rankine and Kulun earth pressure under the limit state, and the structural displacement of the envelope is limited due to the embedding and supporting action of the soil in the foundation pit, and the effect on the envelope earth pressure is the result of the interaction between soil and envelope structure, which is related to the displacement of the envelope, the strength and deformation characteristics of the soil [1-4]. The different earthquakes of the retaining wall have an effect on the size and distribution of the pressure on the retaining structure. The classical earth pressure theory cannot consider the influence of these factors, and study the different deformation methods of the retaining wall Form is the subject to be solved. The numerical analysis of the earth pressure on the rigid retaining wall under different displacement modes shows that the earth pressure of the wall is related to the displacement mode. The displacement mode determines the characteristics of the progressive failure of the filling and the damage forms are different. The earth pressure on the earth wall is the external manifestation of the gradual filling of the wall [5-8].

Based on the analysis of the possible displacement modes of the rigid retaining wall, the active yield characteristics and the progressive development model of the post-wall soil under different displacement modes of the retaining wall are quantitatively analyzed by means of finite element method. The relationship between the limit state and the wall displacement is proposed, and the criterion of the ultimate active earth pressure state is put forward.

\section{Soil Damage Analysis Method Considering Displacement Effect of Retaining Wall}

Analysis model. A Two - dimensional Computational Model Considering the Displacement Effect of Retaining Wall. Rigid retaining wall is $10 \mathrm{~m}$ high, width of wall is $30 \mathrm{~m}$. The model satisfies the posterior wall of the soil as semi-infinite.The soil adopts four-node solid element, the retaining wall adopts beam element, and the finite element grid size is $0.5 \mathrm{~m}$. An X-direction displacement load is applied to the wall. In the retaining wall and the soil between the contact surface to simulate the interaction between soil and structure, mainly for the friction effect.

Calculate parameters. In this paper, the Mohr-Coulomb model is used in the finite element analysis of earth pressure. After the retaining wall soil is isotropic non-cohesive soil, the basic parameters of soil as shown in Table 1. 


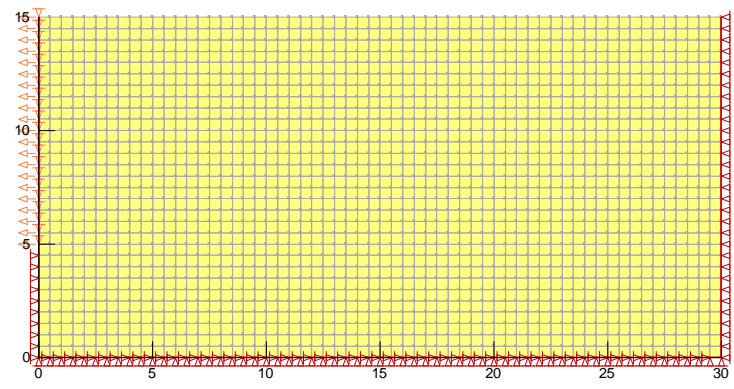

Figure 1 Finite element model

Table 1 Soil basic parameters

\begin{tabular}{ccccc}
\hline $\begin{array}{c}\text { Elastic } \\
\text { modulus/MPa }\end{array}$ & Weight $/ \mathrm{kN} / \mathrm{m}^{3}$ & Cohesion $/ \mathrm{kPa}$ & $\begin{array}{c}\text { Internal friction } \\
\text { angle } /{ }^{\circ}\end{array}$ & Poisson's ratio \\
\hline 18 & 15.6 & 0 & 35 & 0.3 \\
\hline
\end{tabular}

Calculate the rigid retaining wall displacement mode. Calculate three modes of displacement considering the active state, namely T mode, RBT mode and RTT mode. The ratio of the vertical distance to the wall height of the center point of the turning center is $n$. Among them, when the wall is rotated, the calculation of s refers to the maximum displacement of the wall $S_{\max }$, when the RBT mode, $s$ for the wall top displacement; RTT mode, $s$ for the toe displacement.

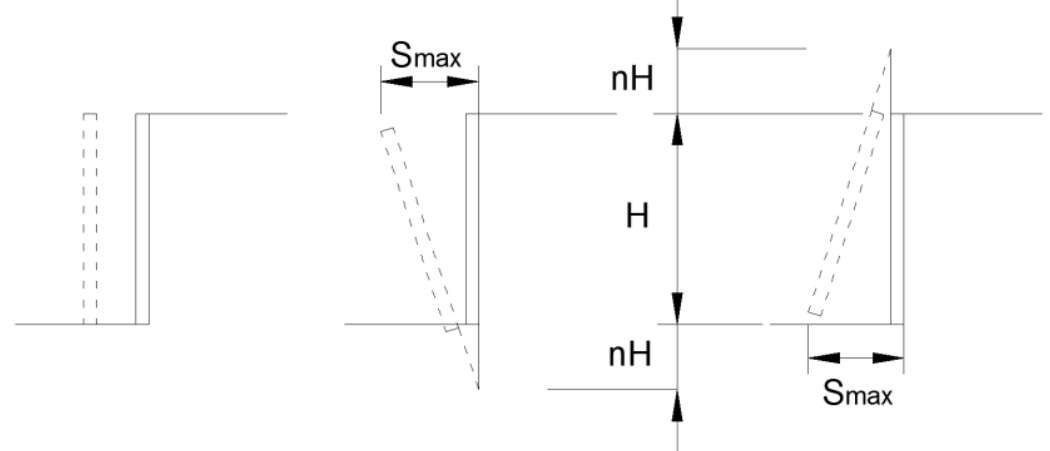

Figure 2 Active state retaining wall T, RBT, RTT displacement mode

\section{Analysis of Active Failure Form in Different Displacement Patterns of Retaining Wall}

Uniform translation ( $\mathbf{T}$ mode).Figure 3 shows the yield damage of the soil after the displacement of the wall, and it can be seen that with the increase of the displacement of the retaining wall, the yield area of the soil is formed by the surface, and then the yield zone From the surface to the deep development, while the toes at the occurrence of yield damage, and with the increase in displacement gradually upward, until the surface with the yield area through, when $s=9 \mathrm{~mm}$, that is, $s / H=0.0009$, the formation of soil Through the sliding surface.

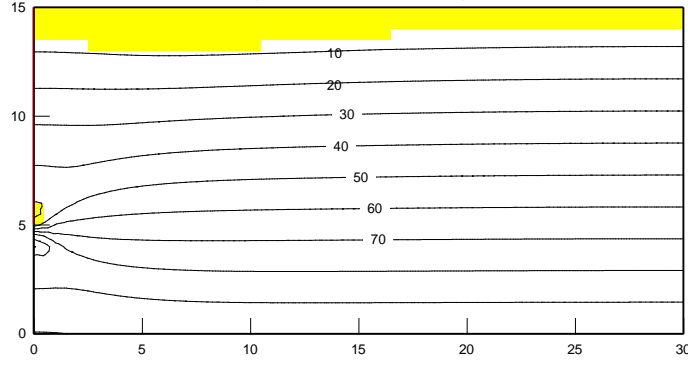

(a) $\mathrm{s}=-0.005 \mathrm{~m}$

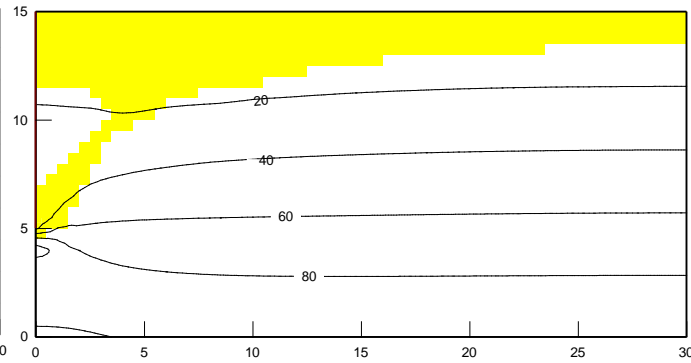

(b) $\mathrm{s}=-0.009 \mathrm{~m}$

Figure 3 Characteristics of soil failure under $T$ mode

Rotate around the bottom (RBT mode). When $n=0$, the soil has the most typical RBT mode failure characteristics. Figure 4 is the wall in the event of different displacement of the rotation, the 
wall after the yield damage. It can be seen that with the increase of the displacement of the retaining wall, the yield area of the soil is extended downward from the surface, near the retaining wall, and the yield area develops rapidly to the deep, forming the broken slip surface. With the wall displacement of the increase, the destruction of the surface gradually moved to the deep, the destruction of the surface and the angle of the horizontal angle is also increasing, but the failure surface has never reached the toe.

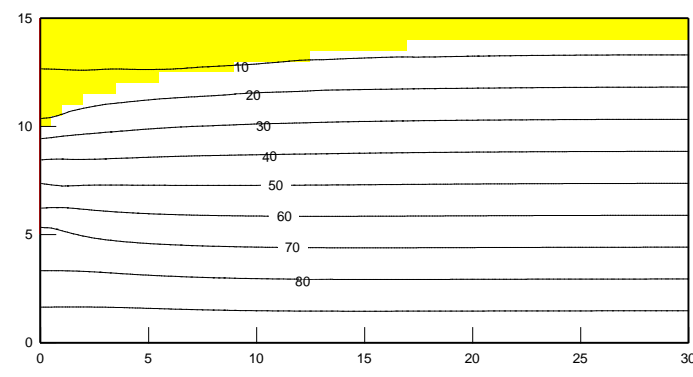

(a) $\mathrm{s}=-0.009 \mathrm{~m}$

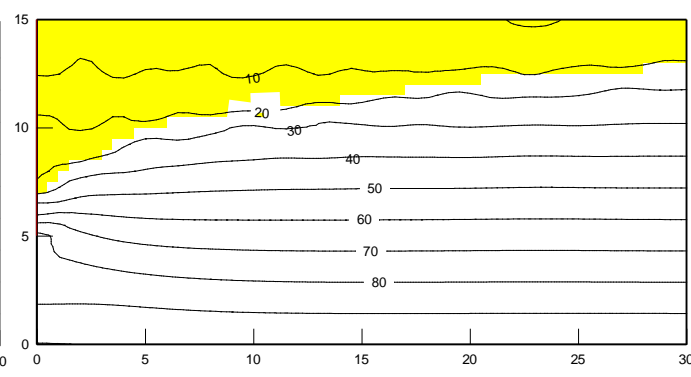

(b) $s=-0.025 \mathrm{~m}$

Figure 4 Characteristics of soil failure under typical RBT mode

Rotate around the top (RTT mode). When $n=0$, the soil has the most typical RBT mode failure characteristics. Figure 5 is the wall in the event of different displacement of the rotation, the wall after the yield damage. It can be seen that with the increase of the displacement of the retaining wall, the yield area of the surface is not obvious. When the displacement is small, the yield area of the soil is formed by the wall toe, and gradually increases with the increase of displacement, until the formation of penetrating slip surface.

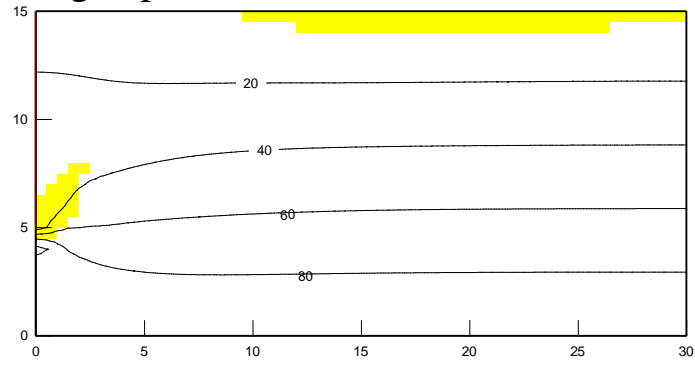

(a) $\mathrm{s}=-0.009 \mathrm{~m}$

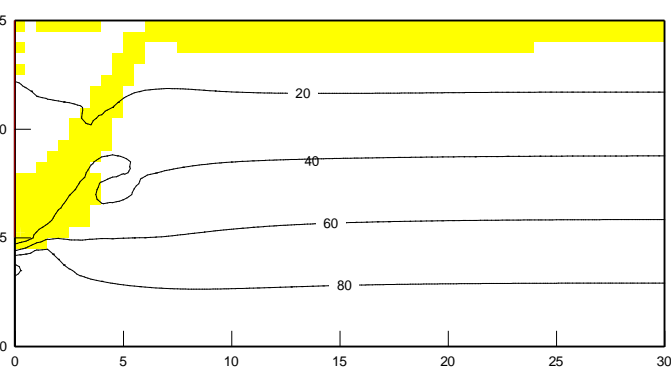

(b) $\mathrm{s}=-0.015 \mathrm{~m}$

Figure 5 Characteristics of soil failure under typical RTT mode

\section{Displacement Analysis of Retaining Wall Under Limit Condition}

In the retaining wall RBT and RTT displacement mode, the rotation point position is different, the wall after the soil to reach the limit state of the displacement value is also different, Table 2 shows the different value of $n$, the ratio between the maximum displacement and the wall height under the ultimate earth pressure state. Figure 6 shows the relationship between the maximum displacement and the wall height required for the soil to reach the limit state.

It can be seen that the displacement of the wall is different when the wall is subjected to the ultimate active earth pressure state under different wall displacement modes. In T mode

$s / H=0.0009$

In the RBT mode and the RTT mode, the $\boldsymbol{s} / \boldsymbol{H}$ and $\boldsymbol{n}$ are basically reciprocal when the soil reaches the ultimate earth pressure state

$s / H=a /(n+b)$

Table 2 The ratio between the maximum displacement and the wall height $(s / H)$

\begin{tabular}{|c|c|c|c|c|c|c|}
\hline \multirow{2}{*}{$\begin{array}{c}\text { Displacement } \\
\text { mode }\end{array}$} & $n=0$ & $n=0.5$ & $n=1.0$ & $n=2.0$ & $n=4.0$ & $n=5.0$ \\
\cline { 2 - 6 } & $>0.0025$ & 0.002 & 0.0016 & 0.0014 & 0.0011 & 0.0009 \\
\hline RBT & $>0.0015$ & 0.0012 & 0.0012 & 0.0011 & 0.0010 & 0.0010 \\
\hline RTT & \multicolumn{6}{|c|}{0.0009} \\
\hline T
\end{tabular}




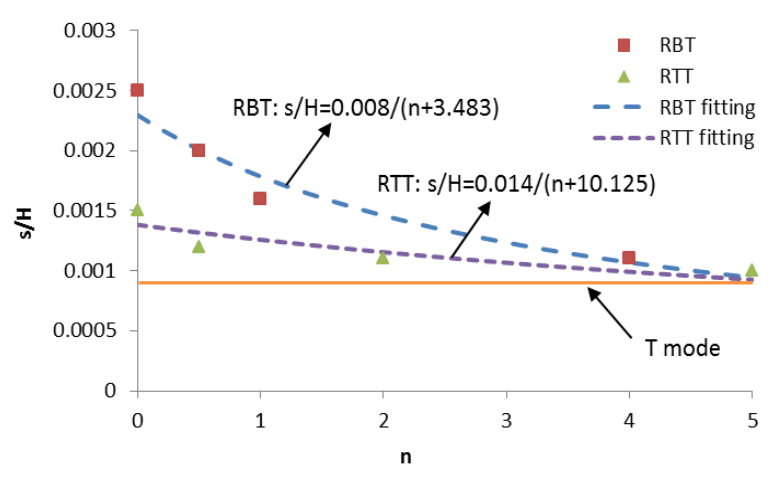

Figure 6 The relationship between $s / H$ and $n$

When the wall's RBT displacement mode occurs, $a=0.008, b=3.483$; when the wall's RTT displacement mode occurs, $a=0.014, b=10.125$, therefore, according to the empirical relationship can be obtained through the location of the point of rotation of the wall The ratio of the maximum displacement to the wall when the wall reaches the limit active state.

The ratio of the limit displacement to the wall height in the RBT mode is equal to the value in the T mode

$$
\begin{aligned}
& (s / H)_{\mathbf{R B T}}=(s / H)_{\mathbf{T}} \\
& 0.008 /(n+3.483)=0.0009
\end{aligned}
$$

Get the $n=5.41$, that is, when the wall is about 5.41 times below the wall toe, the wall pressure state is close to the state when the wall is translating, and the displacement value of the soil reaches the limit state. basically the same.

Similarly, in RTT mode

$$
\begin{aligned}
& (s / H)_{\mathbf{R T T}}=(s / H)_{\mathbf{T}} \\
& 0.014 /(n+10.125)=0.0009
\end{aligned}
$$

Get $n=5.43$, that is, when the wall above the wall of the wall above the 5.43 times the height of the wall when the wall pressure state is close to the state when the retaining wall, the soil reaches the limit state of the displacement value and the wall when the shift basically the same.

Therefore, when the retaining wall is turned, the turning point is located 5 to 6 times the wall outside the wall, the wall pressure state and the wall when the state is basically the same.

\section{Extreme Active Earth Pressure State Criterion}

At a time when the retaining wall rotates, take RBT and RTT displacement modes as an example (see Figure 7).

$$
\begin{aligned}
& n H /(n+1) H=s_{1} / s_{0} \\
& n=s_{1} /\left(s_{0}-s_{1}\right)
\end{aligned}
$$

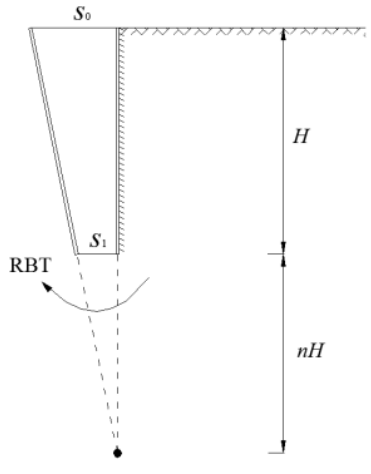

(a) RBT

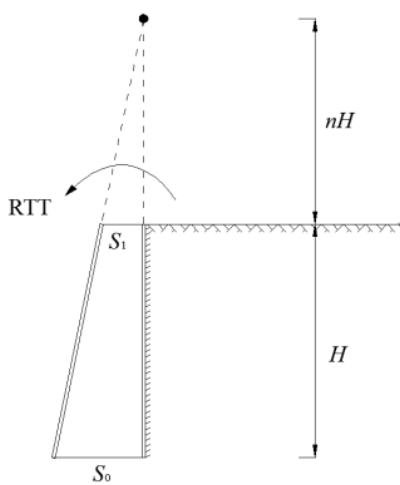

(b) RTT

Figure 7 RBT and RTT displacement mode under the retaining wall diagram 
In the actual project, if the displacement mode of the retaining wall is RBT mode, the displacement of the wall top is larger than that of the toe displacement, and the displacement amount $s_{0}$ and $s_{1}$ of the immediate wall and the toe can be obtained through the displacement monitoring of the retaining wall. And then the maximum displacement $s$ of the wall top is calculated by the empirical formula of the limit state of the soil in RBT mode. Compared with $\mathrm{s}_{0}$ and $\mathrm{s}$, if $s_{0} \geq s$, the wall has reached the limit active earth pressure state, if $s_{0}<s$, the wall after the soil did not reach the limit of active earth pressure state. If the displacement mode of the retaining wall is RTT mode, the displacement of the wall top is smaller than that of the toe displacement, and the displacement amount $s_{1}$ and $s_{0}$ of the immediate wall and the toe can be obtained by the displacement monitoring of the retaining wall. According to the empirical formula of the limit state of the soil in the RTT model, the maximum displacement of the wall toe is calculated, and the $s_{0}$ and $s$ are compared. If $s_{0} \geq s$, the wall has reached the ultimate active earth pressure, if $s_{0}<s$, the wall The soil does not reach the ultimate active earth pressure state.

\section{Summary}

The active yield characteristics and the progressive development model of the post-wall soil under different displacement modes of the retaining wall are quantitatively analyzed. When $n$ are different, the ratios between the maximum displacement and the wall height under the ultimate earth pressure state are found. The criterion of the ultimate active earth pressure state is put forward.

\section{References}

[1] Ren, Chuan Jian, and H. B. Jia. The Influence of Unsaturated Soil's Characteristics on Rankine Earth Pressure. Science Technology \& Engineering (2015).

[2] Zhao, Jun Hai, et al. Unified Solution of Rankine's Earth Pressure of Unsaturated Soil Under Rainfall. Journal of Architecture \& Civil Engineering (2016).

[3] Ying, Hong Wei, et al. Experimental analysis of passive earth pressure against rigid retaining wall under translation mode for finite soils. Chinese Journal of Geotechnical Engineering (2016).

[4] He, S., Z. Wang, and J. Wang. Research on the earth pressure distribution behind the retaining wall under seismic acceleration influence. Journal of Sichuan University 47.4(2015):31-37.

[5] Sabzevari, Ali, and A. Ghahramani. Theoretical investigations of the passive progressive failure in an earth pressure problem. Soils \& Foundations 13.2(1973):1-18.

[6] Woodward, P. K. Earth pressure coefficients based on the Lade-Duncan failure criterion. Engineering Structures 19.9(1997):733-737.

[7] Yang, Ming Hui, et al. Experimental study on active earth pressure of cohesionless soil with limited width behind retaining wall. Chinese Journal of Geotechnical Engineering (2016).

[8] Cai, Yanyan, et al. Estimation of Passive Earth Pressure against Rigid Retaining Wall Considering Arching Effect in Cohesive-Frictional Backfill under Translation Mode. International Journal of Geomechanics (2016). 